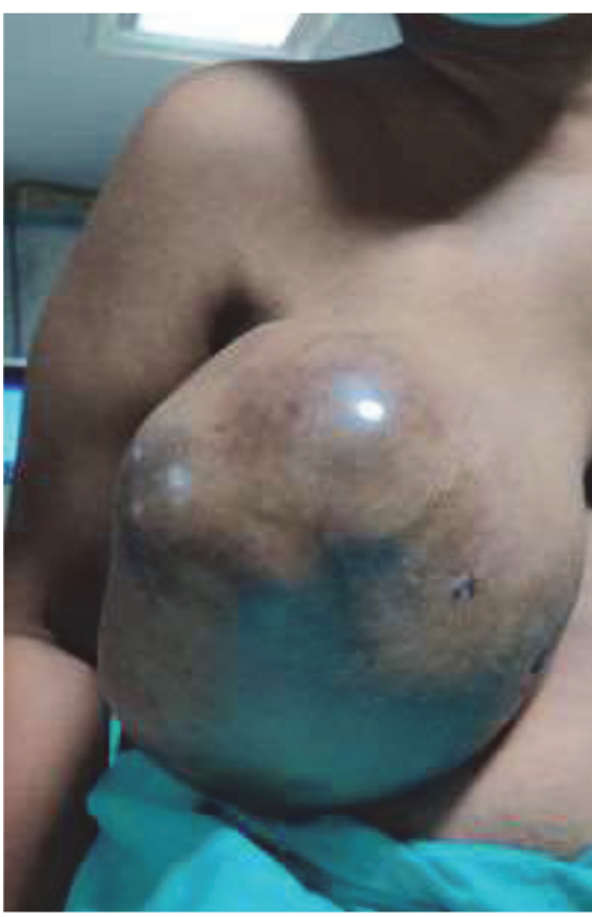

Abstract 21 Figure 1

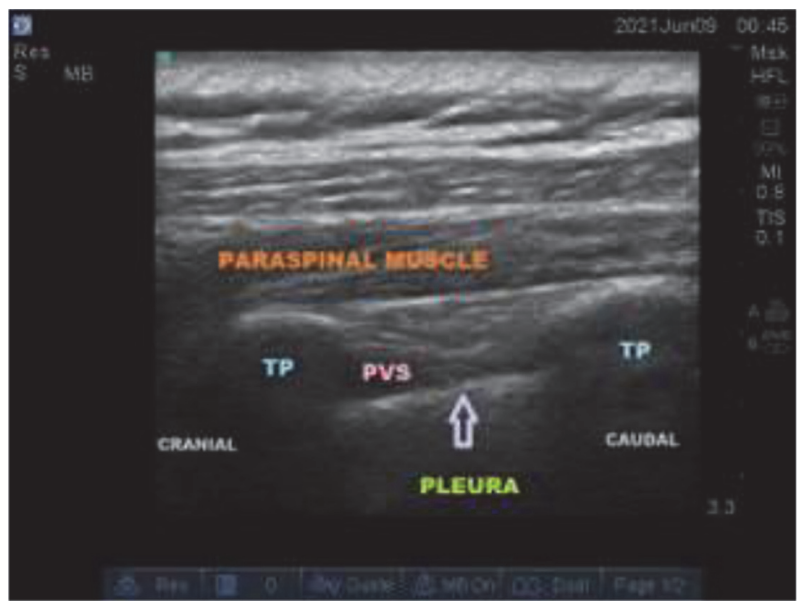

Abstract 21 Figure 2

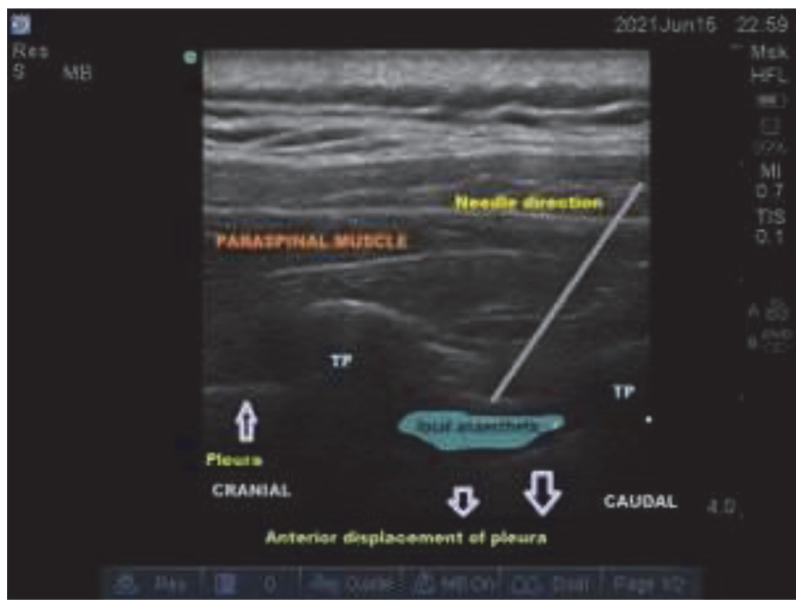

Abstract 21 Figure 3

\section{SACROILIETIS IS A LEADING CAUSE OF FAILED BACK SURGERY SYNDROME: A CASE STUDY}

V Kanojiya*, R Jain. L.N.Medical College and Research Center, Bhopal, India

\subsection{6/rapm-2021-ESRA.22}

Background and Aims Most people experience low back pain at some point in their life with one common cause of back pain. In particular, SI joint pain causes axial back pain affecting between 15 and $25 \%$ of people. Pain generated in the SI joint or surrounding structures can present as low back pain, leg pain, sacral pain, pelvic pain, or gluteal pain.Unilateral pain is more common than bilateral. It may be the result of direct trauma, unidirectional pelvic shear, repetitive and torsional forces Sacroiliac joint pain mostly diagnosed based upon the history and physical examination test.

Currently, most reliable method of diagnosing SIJ pain is a diagnostic block of local anaesthetic directly into the SIJ.Current evidence favours lateral branch radiofrequency (RF) lesioning as the most effective treatment.Moreover,it is an alternative treatment.

Methods Patient developed failed back surgery syndrome for which after discussion with neurosurgeon and patient we have decided to give diagnostic Right SI joint block using inj bupivacaine $0.25 \%$ with Triamcilone $40 \mathrm{mg}$ under fluoroscopy with dye guidance. Informed consent taken.Post procedure no neurological deterioration.Patient was kept in hospital for 2 hours and then discharged.
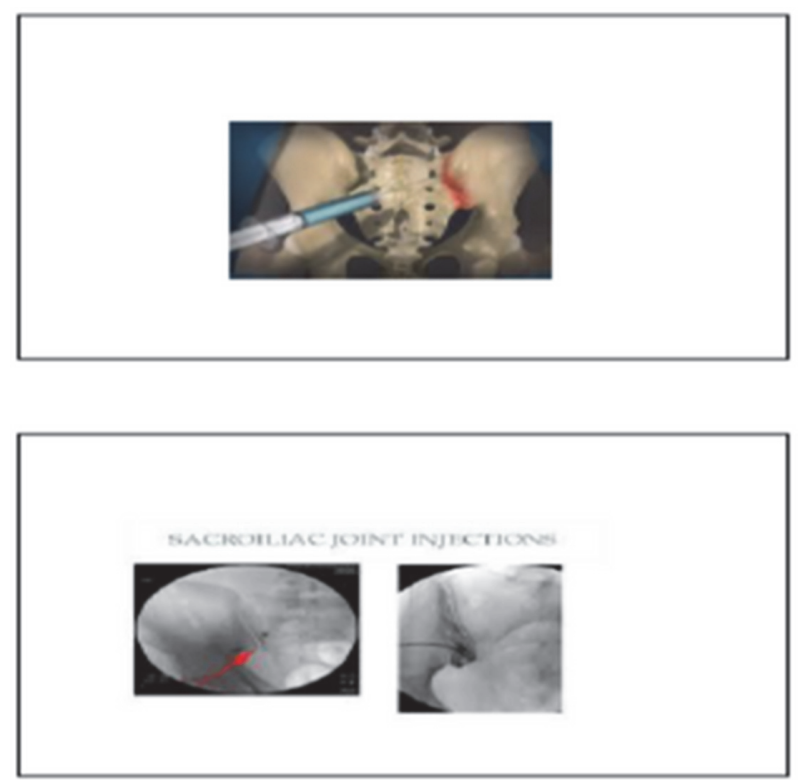

Abstract 22 Figure 1

Results Right SI Joint block under fluoroscpic guidance was performed uneventfully. Post procedure no neurological deterioration. After 2 hours patient got 50\% pain relief.All analgesics stopped,Pregabalin was tapered and patient discharged.

Conclusions Interventional pain procedures are minimally invasive day care procedures. In properly selected patients they can prevent surgery, cost effective also decreases Morbidity. If pain is resistant and significant neurological deficit is not there they can prevent unnecessary surgery. 